\title{
MICROHARDNESS EVALUATION AROUND COMPOSITE RESTORATIONS USING FLUORIDE-CONTAINING ADHESIVE SYSTEMS
}

\author{
AVALIAÇÃO DA MICRODUREZA AO REDOR DE RESTAURAÇÕES DE COMPÓSITO \\ CONFECCIONADAS COM SISTEMAS ADESIVOS CONTENDO FLUORETOS
}

\author{
Cláudia Silami de MAGALHÃES ${ }^{1}$, Anderson Takeo HARA², Cecilia Pedroso TURSSI ${ }^{3}$, \\ Mônica Campos SERRA ${ }^{4}$, Marcelo GIANNINI ${ }^{5}$
}

\begin{abstract}
1- DDS, MSc, PhD, Assistant Professor, Department of Restorative Dentistry, Dental School, Federal University of Minas Gerais, Belo Horizonte, MG, Brazil. 2- DDS, MSc, Graduate Student (Doctor Degree), Department of Restorative Dentistry, Piracicaba Dental School, State University of Campinas, Piracicaba, SP, Brazil.

3- DDS, MSc, PhD, Graduate Student (Doctor Degree), Department of Restorative Dentistry, Piracicaba Dental School, State University of Campinas, Piracicaba, SP, Brazil.

4- DDS, MSc, PhD, Associate Professor, Department of Restorative Dentistry, Ribeirão Preto Dental School, University of São Paulo, Ribeirão Preto, SP, Brazil. 5- DDS, MSc, PhD, Associate Professor, Department of Restorative Dentistry, Piracicaba Dental School, State University of Campinas, Piracicaba, SP, Brazil.

Corresponding address: Prof. Dr. Marcelo Giannini - Departamento de Odontologia Restauradora - Faculdade de Odontologia de Piracicaba - Universidade Estadual de Campinas - Av. Limeira 901 - Piracicaba / SP - CEP 13414-018 - Brasil - Phone: 5519 3412-5338

Fax: 5519 412-5218 - e-mail: giannini@fop.unicamp.br
\end{abstract}

Received: September 21, 2004 - Modification: February 28, 2005 - Accepted: May 09, 2005

\begin{abstract}
$T_{\mathrm{h}}$

he purpose of this study was to evaluate the microhardness of dental enamel around composite restorations bonded with fluoride-containing adhesive systems (FCAS), after thermo- and $\mathrm{pH}$-cycling protocols. Standardized cylindrical cavities were prepared on enamel surfaces of 175 dental fragments, which were randomly assigned into seven experimental groups ( $\mathrm{n}=25)$. Four groups used FCAS: Optibond Solo (OS); Prime\&Bond 2.1 (PB); Syntac Sprint (SS) and Tenure Quick (TC). Other groups consisted of "Sandwich" technique restoration (STR) (glass ionomer liner + hydrophobic adhesive resin /restorative composite) or used Single Bond with (SB) or without (SBWC) cycling protocols. Adhesive systems were applied according to manufacturers' instructions and cavities were restored with a microfilled composite (Durafill VS). After finishing and polishing, all groups were submitted to 1,000 thermal cycles $\left(5{ }^{\circ} \mathrm{C}\right.$ and $\left.55{ }^{\circ} \mathrm{C}\right)$ and to demineralization $(\mathrm{pH} 4.3)$ and remineralization (pH 7.0) cycling protocols, except for SBWC group. The Knoop microhardness of enamel surfaces were measured around restorations. Indentations were recorded at 150, 300 and 450-mm from the cavity wall. Data were analyzed by two-way ANOVA and Duncan's Test (a=0.05\%). Means \pm SD of enamel microhardness for the groups were $\left(\mathrm{Kg} / \mathrm{mm}^{2}\right)$ : SBWC: $314.50 \pm 55.93^{\mathrm{a}}$; SB: $256.78 \pm 62.66^{\mathrm{b}}$; STR: $253.90 \pm 83.6^{\mathrm{b}}$; TQ: $243.93 \pm 68.3^{\mathrm{b}}$; OS: $227.97 \pm 67.1^{\text {c; }}$ PB: $213.30 \pm 91.3^{\text {d; }}$ SS: $208.73 \pm 86.6^{\text {d }}$. Means \pm SD of microhardness for the distances $150,300,450 \mathrm{~mm}$ from the cavity wall were, respectively: $234.46 \pm 77.81^{\mathrm{a}}$; $240.24 \pm 85.12^{\mathrm{a}}$; $262.06 \pm 79.46^{\mathrm{b}}$. SBWC group, which was not submitted to thermo- and pH-cycling protocols, showed the highest enamel microhardness mean value and the FCAS resulted in lower microhardness values. At $450 \mathrm{~mm}$ from the cavity wall, the enamel microhardness increased significantly.

Uniterms: Dental enamel; Fluoride; Adhesive systems; Microhardness.
\end{abstract}

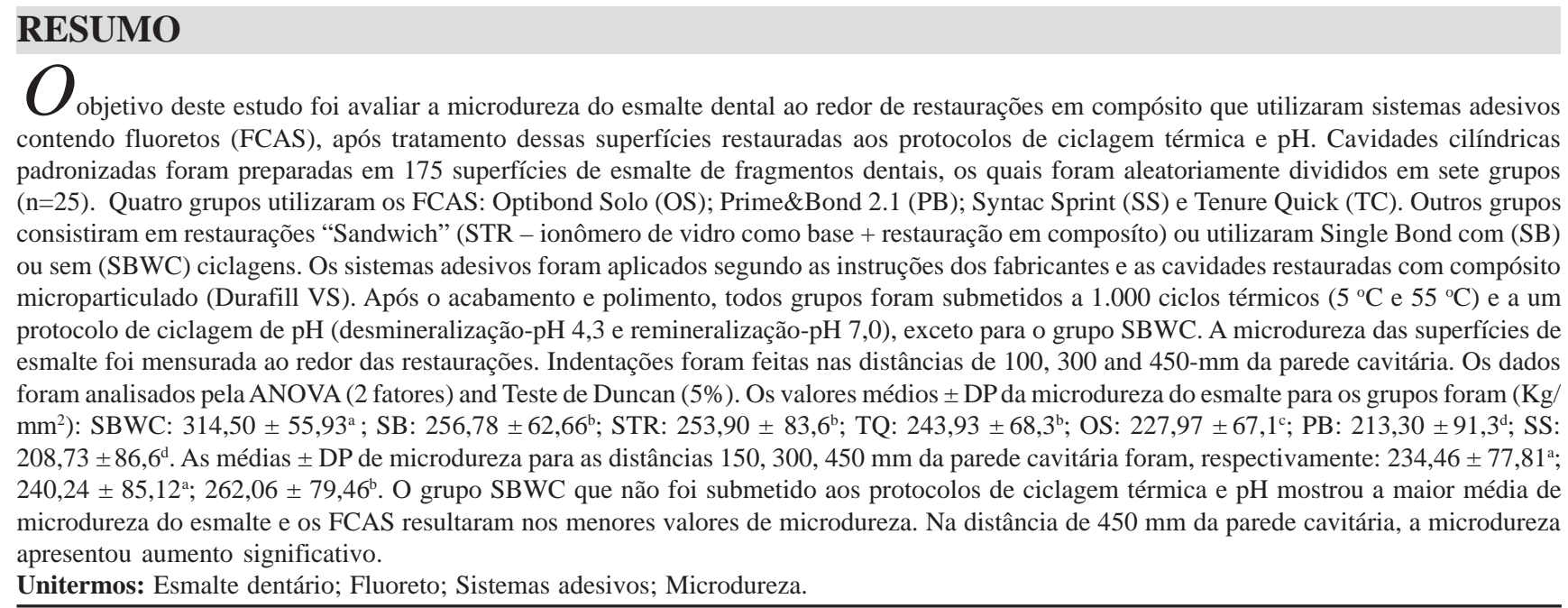




\section{INTRODUCTION}

Adhesive systems have promoted high bond strengths to dental hard tissues ${ }^{5,7,21}$. However, secondary caries is still the reason most commonly cited for the replacement of composite restorations ${ }^{3,9,14}$. The deficient marginal adaptation and lack of cavity sealing may allow fluid and bacteria infiltration, leading to caries lesions development in the tooth structure along the restorative interface ${ }^{20}$. In fact, an in vivo study has shown that at gap-free regions there is no wall lesion development, emphasizing the critical role of marginal sealing in restoration integrity ${ }^{12}$.

Besides the sealing properties, secondary caries incidence can be assigned to the anticariogenic effect of restorative materials. Thus, approaches that inhibit the ingress of metabolic products of biofilm into the microgap between tooth and restoration, increase resistance to demineralization, and/or facilitate remineralization are of considerable clinical interest ${ }^{6}$.

As numerous investigations have shown the ability of fluoride-containing materials to inhibit caries activity around restorations, continuing research into the development of other materials for delivering fluoride in a form that will be effective is ongoing 3,6,9,14,16,18,11,19. Glass-ionomer and resinmodified glass ionomer cements have been formulated as cavity liners ${ }^{10,15}$. Also, many bonding agents, total-etch dentin adhesives, and one-bottle adhesives containing fluoride have become available. The objective of these materials is to produce long-lasting restorations, providing protection against secondary caries.

Even though fluoride-releasing products directly contact the cavity wall, there is little evidence regarding the amount of fluoride ions released from them, their diffusion into the cavity wall and their effects on surrounding tooth structure $^{4,9,14,17,18}$.

Because bonding agents play a crucial role and are strategically positioned in a restoration, this in vitro study evaluated the enamel microhardness around composite restorations bonded with fluoride-containing one-bottle adhesive systems, after thermal and demineralization/ remineralization cycling protocols. The specific null hypotheses tested were: (1) there are no differences among the enamel microhardness around composite restorations bonded with different adhesive systems and techniques; and (2) there are no differences of microhardness along different distances from the cavity wall.

\section{MATERIALS AND METHODS}

\section{Experimental Design}

The factors under study were adhesive systems/ restorative techniques at seven levels and distance from the restoration cavity wall at three levels (150, 300, 450mm). The experimental units were 175 dental fragments $(n=25)$, randomly restored in 25 blocks of 7 fragments each. Each block contained one fragment of each one of the seven groups. A randomized complete block design was used to systematically control the variability arising from known nuisance sources. As it was not possible to completely randomize the order in which the distances from the cavity wall were analyzed, this investigation characterized a factorial $7 \mathrm{x} 3$ split-plot design ${ }^{11}$. The continuous response variable was Knoop microhardness.

\section{Preparation of samples}

Forty unerupted, extracted human third molars, stored in $2 \%$ formaldehyde solution $(\mathrm{pH}=7.0)$ for no longer than two months after extraction were used in this study. The teeth were cleaned of gross debris and placed in deionized water for $24 \mathrm{~h}$ at $8^{\circ} \mathrm{C}$ prior to beginning of the experimental procedures. The crowns were sectioned longitudinally to obtain 175 dental fragments (5mm width $\mathrm{x} 5 \mathrm{~mm}$ length $\mathrm{x}$ 4mm height) using a diamond blade (\#7020 - KG Sorensen Ind. e Com. Ltda, Barueri, SP, Brazil).

\section{Cavity preparation and restorative procedures}

Standard cylindrical-shaped cavities (2mm diameter and $1.5 \mathrm{~mm}$ depth) were prepared on the enamel surface of each fragment, using a cylindrical diamond bur (\#2096, KG Sorensen) mounted in a high-speed turbine with air-water coolant. Dental fragments were then randomly assigned into 7 groups $(\mathrm{n}=25)$, according to the adhesive systems/ restorative techniques studied.

The materials used in this study were four fluoridecontaining one-bottle adhesive systems: Optibond Solo ( Kerr Corp., Orange, CA, USA); Prime\&Bond 2.1 (Dentsply De Trey, Konstanz, Germany); Syntac Sprint (Vivadent, Schaan, Liechtenstein) and Tenure Quick (Den-Mat Corp., Santa Maria, CA, USA), a non-fluoride-containing one-bottle adhesive-system (Single Bond, 3M/ESPE, St. Paul, MN, USA), a resin-modified glass ionomer liner (Vitrebond, 3M/ ESPE) and a non-fluoride adhesive resin (Durafill Bond, Heraeus Kulzer GmbH, Dormagen, Germany) (Table 1).

All materials, adhesives and restoratives, were applied according to manufacturers' instructions (Table 2). Bonded cavities were bulk-filled with microfill composite (Durafill VS, Heraeus Kulzer GmbH) and light-cured for 40 s (Optilux 500, Demetron Corp., Danbury, CT, USA). A group comprised "Sandwich" technique restorations ${ }^{10}$ with Vitrebond as liner ( $0.7 \mathrm{~mm}$ thickness) and Durafill Bond / Durafill VS restorative system. Single Bond adhesive was used in two groups: one group was subjected to the thermo and $\mathrm{pH}$-cycling protocol and the other was not. Experimental groups were as follows:

Group 1- Restored with Single Bond adhesive + Durafill VS microfilled composite (not submitted to cycling protocols and was kept in $100 \%$ relative humidity at $37^{\circ} \mathrm{C}$ ).

Group 2- Restored with Single Bond adhesive + Durafill VS microfilled composite (subjected to cycling protocols).

Group 3- Restored with Vitrebond (liner) + Durafill Bond adhesive + Durafill VS microfilled composite (Sandwich” technique) (subjected to cycling protocols).

Group 4- Restored with Tenure Quick adhesive + Durafill 
VS microfilled composite (subjected to cycling protocols). Group 5- Restored with Optibond Solo adhesive + Durafill VS microfilled composite (subjected to cycling protocols). Group 6- Restored with Prime\&Bond 2.1 adhesive + Durafill VS microfilled composite (subjected to cycling protocols).

Group 7- Restored with Syntac Sprint adhesive + Durafill VS microfilled composite (subjected to cycling protocols).

Restored samples were stored in 100\% relative humidity for $48 \mathrm{~h}$ at $37^{\circ} \mathrm{C}$ and polished with Sof Lex discs (3M ESPE), ensuring that there were no overhangs at margins.

\section{Thermo- and pH-cycling}

Except for Group 1, all experimental groups (2 to 7) were submitted to thermal and demineralization/remineralization cyclings ${ }^{19}$. The restored enamel surfaces were covered with nail varnish leaving exposed only the restorations and $2 \mathrm{~mm}$ of enamel surface around them. These specimens were thermocycled (MCT2 - AMM, Instrumental Ltda, São Paulo, SP, Brazil) for 1,000 cycles in distilled water at $5^{\circ} \mathrm{C}$ and $55^{\circ} \mathrm{C}$ with a dwell time of $1 \mathrm{~min}$.

Each restored sample was placed in $15 \mathrm{~mL}$ of demineralizing solution $(2.0 \mathrm{mM}$ of calcium, $2.0 \mathrm{mM}$ of phosphate in a buffer solution of $74 \mathrm{mM}$ of acetate at $\mathrm{pH}=$ 4.3) for $6 \mathrm{~h}$ at $37^{\circ} \mathrm{C}$, followed by rinsing with deionized water and immersion in $15 \mathrm{~mL}$ of remineralizing solution $(1.5 \mathrm{mM}$ of calcium and $0.9 \mathrm{mM}$ of phosphate in a buffer solution of $20.0 \mathrm{mM}$ of tris (hydroxymethil)-aminomethane at $\mathrm{pH}=7.0$ ) for $18 \mathrm{~h}$ at $37^{\circ} \mathrm{C}$. After five $\mathrm{pH}$ cycles had been performed, each specimen was stored in $15 \mathrm{~mL}$ of remineralizing solution for 2 days at $37^{\circ} \mathrm{C}$.

\section{Preparation of specimens for microhardness measurements}

At the end of each treatment period, restored specimen were rinsed in deionized water and longitudinally sectioned through the center of the restoration with a slow-speed diamond saw (KG Sorensen Ind. e Com. Ltda). A half of the specimen was embedded in polystyrene resin and its restored surface was wet-polished with 600- and 1000-grit SiC (Carborundum Abrasivos Ltda, Vinhedo, SP, Brazil). Final polishing was performed with diamond abrasive pastes (6 $\mu \mathrm{m}, 3 \mu \mathrm{m}, 1 \mu \mathrm{m}$ and $0.25 \mu \mathrm{m}$ - Buehler Ltd., Lake Bluff, IL, USA) on cloths, under mineral oil lubrication.

Microhardness measurements were carried out on the leveled enamel subsurface of each dental slab with a microhardness tester (FM-1, Future Tech, Tokyo, Japan) and a Knoop indenter. Nine indentations with 25g applied for $5 \mathrm{~s}$ were made in each sample. Three measurements were taken at the distance of $150 \mu \mathrm{m}, 300 \mu \mathrm{m}$ and $450 \mu \mathrm{m}$ from the

TABLE 1- Compositions of evaluated materials and procedures for bonding according to manufacturers' instructions

\begin{tabular}{|c|c|c|c|}
\hline $\begin{array}{l}\text { Material I } \\
\text { Manufacturer }\end{array}$ & Composition & Procedure & Lot number \\
\hline OptiBond Solo & $\begin{array}{l}\text { Etching gel: } 37.5 \% \text { phosphoric acid } \\
\text { Adhesive: GPDM, HEMA, Bis-GMA, barium } \\
\text { aluminoborosilicate,sodium hexafluorosilicate and etanol }\end{array}$ & a (15 s); b; c; d; h (20 s) & 705794 \\
\hline Prime\&Bond 2.1 & $\begin{array}{l}\text { Etching gel: } 36 \% \text { phosphoric acid } \\
\text { Adhesive: PENTA, elastomeric dimethacrylate resins, } \\
\text { cetylamine hydrofluoride and acetone }\end{array}$ & $\begin{array}{l}\text { a (15 s); b; c; d (2 coats); } \\
\text { h (10 s) }\end{array}$ & 35004 \\
\hline Single Bond & $\begin{array}{l}\text { Etching gel: } 35 \% \text { phosphoric acid } \\
\text { Adhesive: HEMA, Bis-GMA, PAA, ethanol and water }\end{array}$ & $\begin{array}{l}\text { a (15 s); b; c; d (2 coats); } \\
\text { h (10 s) }\end{array}$ & $7 U-1105$ \\
\hline Syntac Sprint & $\begin{array}{l}\text { Etching gel: } 37 \% \text { phosphoric acid } \\
\text { Adhesive: HEMA, maleic acid, methacrylate-modified } \\
\text { polyacrylic acid, fluoride compound and water }\end{array}$ & a (15 s); b; c; d; h (10 s) & A01614 \\
\hline Tenure Quick & $\begin{array}{l}\text { Etching gel: } 37 \% \text { phosphoric acid } \\
\text { Adhesive: Dimethacrylate resin, HEMA, PMDM, } \\
\text { fluoride and acetone }\end{array}$ & $\begin{array}{l}\text { a (15 s); b; c; d (3 coats); } \\
\text { h (15 s) }\end{array}$ & 227012 \\
\hline Vitrebond & $\begin{array}{l}\text { Powder: Fluoro-aluminosilicate glass } \\
\text { Liquid: Polyalkenoic acid and HEMA }\end{array}$ & $\mathrm{e} ; \mathrm{f} ; \mathrm{h}(30 \mathrm{~s})$ & 19980310 \\
\hline Durafil Bond & Adhesive: Bis-GMA and TEG-DMA & $\begin{array}{l}\text { a (15 s); b; g; d; } \\
\text { h (20 s) }\end{array}$ & CE0123-30 \\
\hline
\end{tabular}

Procedures - a: acid etching; b: rinse; c: gently air; d: apply adhesive; e: mix powder + liquid; f: apply mixture; g: air dry; h: light cure Abbreviations - Bis-GMA: bisphenol-glycidyl methacrylate; HEMA: 2-hydroxyethyl methacrylate; GPDM: glycerophosphate dimethacrylate; PAA: polyalkenoic acid copolymer; PENTA: dipentaerythritol penta-acrylate monophosphate; PMDM: pyromellitic dimethacrylate; TEG-DMA: triethylene glycol dimethacrylate. 
restoration cavity wall. For each distance indentations were taken at 30 to $90 \mu \mathrm{m}$ from the outer enamel surface. The microhardness values derived by the equation: Knoop Hardness $=14229 . \mathrm{K} / \mathrm{L}^{2}$, where $\mathrm{K}$ is the applied load in grams, and $\mathrm{L}$ is the indentation length, in micrometers.

\section{Statistical analysis}

After checking of the assumptions of homogeneity of variance (Hartley's test) and normal distribution (ShappiroWilks), the response variable cross-sectional enamel Knoop microhardness was analyzed using a two-way analysis of variance (ANOVA) considering the significance level of 5\%. The effect of the factors Adhesive System and Distance from the restoration was evaluated, as well as the interactions of those variation sources. Multiple Comparison Duncan's test was applied to detect significant differences among groups $(\mathrm{a}=0.05 \%)$.

\section{RESULTS}

Mean values of microhardness for restorative procedures and distances from the restoration cavity wall are displayed in Tables 2 and 3, respectively. ANOVA did not show significant interaction between adhesive systems and distances from the restoration $(p=0.98)$. Significant effects were detected for adhesive systems $(p=0.0083)$ and distance from the cavity wall $(\mathrm{p}=0.0188)$.

TABLE 2- Mean Knoop microhardness values $\left(\mathrm{Kg} / \mathrm{mm}^{2}\right)$ for restorative procedures

\begin{tabular}{lc}
$\begin{array}{l}\text { Restorative } \\
\text { procedure }\end{array}$ & $\begin{array}{c}\text { Knoop microhardness } \\
\text { (mean } \pm \text { SD) }\end{array}$ \\
\hline Single Bond* $^{\star}$ & $314.50 \pm 55.93^{\mathrm{a}}$ \\
Single Bond $^{\mathrm{V}}$ & $256.78 \pm 62.66^{\mathrm{b}}$ \\
Vitrebond / Durafil Bond $_{\text {Tenure Quick }}$ & $253.90 \pm 83.61^{\mathrm{b}}$ \\
Optibond Solo & $243.93 \pm 68.33^{\mathrm{b}}$ \\
Prime\&Bond 2.1 & $227.97 \pm 67.19^{\mathrm{c}}$ \\
Syntac Sprint & $213.30 \pm 91.34^{\mathrm{d}}$ \\
\hline
\end{tabular}

* Group did not subject to thermal and pH cyclings.

Different letters indicate significant differences among groups $(p<0.05)$.

TABLE 3- Mean Knoop microhardness values $\left(\mathrm{Kg} / \mathrm{mm}^{2}\right)$ for measurement locations

\begin{tabular}{lc}
$\begin{array}{l}\text { Distance from } \\
\text { cavity wall }(\mu \mathrm{m})\end{array}$ & $\begin{array}{c}\text { Knoop microhardness } \\
(\text { mean } \pm \text { SD) }\end{array}$ \\
\hline 150 & $234.46 \pm 77.81^{\mathrm{a}}$ \\
300 & $240.24 \pm 85.12^{\mathrm{a}}$ \\
450 & $262.06 \pm 79.46^{\mathrm{b}}$ \\
\hline
\end{tabular}

Different letters indicate significant differences among groups $(p<0.05)$.
Duncan's test showed that the group restored with Single Bond not subject to both, thermal and $\mathrm{pH}$ cycling, presented the highest microhardness mean around the restoration ( $\mathrm{p}<0.05)$. Groups restored with Single Bond, Vitrebond / Durafill Bond - Durafil VS (NC) and Tenure Quick exhibited higher microhardness than Optibond Solo, Prime\&Bond 2.1 and Syntac Sprint. Prime\&Bond 2.1 and Syntac Sprint presented the lowest microhardness values and were not statistically different from each other (Table 2).

The comparison of microhardness at different locations (Table 3) indicated that the first two measurements that were closer to the cavity wall (150 and 300 $\mu \mathrm{m})$ presented lower microhardness means than the values obtained at $450 \mu \mathrm{m}$ from the cavity wall.

\section{DISCUSSION}

In vitro evaluations of induced caries-like lesions around restored cavities are important to analyze the behavior of restorative materials on the development of caries $^{3,9,14,16-19}$. On the basis of this statement, this study was designed to verify the effects of enamel demineralization adjacent to composite restorations bonded with fluoride-containing adhesive systems. The enamel demineralization was produced by a $\mathrm{pH}$-cycling model that tries to simulate highly cariogenic oral conditions.

High quality sealing of the cavity margins is necessary for the establishment of long lasting restorations ${ }^{20}$. Even though bonding of composite restorative materials to enamel has been considered a durable and effective procedure, microleakage may occur and be detrimental for the longevity of the restorations. Thermal cycling regimen was adopted to simulate the temperature extremes conform those found in the oral cavity. Resin adhesive volumetric shrinkage and expansion $^{2}$ during thermal cycling may stress and damage the bond. Marginal gaps formation and/or presence of microporosities at the bonded interfaces could favour $\mathrm{pH}$ cycling-induced demineralization of the cavity wall ${ }^{8,19}$. In this current study, the analysis of microhardness showed lower values at $150 \mu \mathrm{m}$ and $300 \mu \mathrm{m}$ from restoration, which can be related to restorations effects.

Because dental caries comprise a process of alternating demineralization and remineralization phenomena, enamel microhardness reduction adjacent to bonded restorations were promoted by a dynamic model that simulates in vivo conditions of high caries risk ${ }^{19}$. The effectiveness of the adopted cariogenic challenge in producing demineralization was confirmed, as there was statistically significant difference between cycled (Group 2) and non-cycled (Group 1) specimens bonded with Single Bond. Following thermoand $\mathrm{pH}$-cyclings, all groups presented lower microhardness than Group 1, which represented sound enamel around restoration. Thus, no restorative technique completely avoids the demineralization areas formation around restorations. However, some restorative procedures provided higher enamel microhardness values around 
composite restorations than others, suggesting a different behavior of composite restorative/bonding agent systems.

The Single Bond one-bottle adhesive that does not contain fluoride, the "sandwich" technique that comprised the association of glass-ionomer cement/composite resin ${ }^{10,15}$ and a fluoride-containing one-bottle system (Tenure Quick) provided lower demineralization than the other restorative procedures. Therefore, the reduction of microhardness was not dependent on fluoride presence in the adhesive composition. Cariostatic properties of glass-ionomer cements are related to the fluoride release, which can reduce demineralization on enamel around restorations ${ }^{1,14,16,19}$. However, the marginal sealing promoted by Durafil Bond adhesive resin, which is not a fluoride-containing adhesive may have blocked the direct access to fluoride from the resin-modified glass-ionomer (Vitrebond) to adjacent demineralized areas, when the "sandwich" technique was used. Even though "sandwich" restorative technique did not reach microhardness values obtained for Group 1 (Single Bond) that was not submitted to thermal and $\mathrm{pH}$-cyclings, it showed higher microhardness than three fluoride-containing adhesive systems (OS, PB and SS).

Simplification of bonding procedures led manufactures to combine the primer and adhesive resin into a single bottle. These bonding agents are directly placed on dentin and enamel following the "total-etch technique" with phosphoric acid. One-bottle adhesive systems have also been evaluated regarding the bond strength and interfacial micromorphology $y^{5,713,21}$ and some of these studies have demonstrated that Tenure Quick provided low bond strength values and incomplete infiltration of monomers into the mineralized dental structures ${ }^{7,13,21}$. However, in this study, it was among the total-etch fluoride-containing adhesives that produced the highest microhardness values, i.e., lowest reduction on enamel demineralization adjacent to composite restoration. Although manufacturers do not show the source of fluoride and do not explain the fluoride-releasing mechanism, it is possible that the concentration of fluoride ions and the mode of releasing may have influenced results $s^{4,8,19}$

Studies have shown that Single Bond adhesive promotes high bond strengths and a consistent adhesion to tooth substrate, however the efficacy of Prime\&Bond 2.1, Optibond Solo and Syntac Sprint has not been established ${ }^{7,13,21}$. For Prime\&Bond 2.1, the source of fluoride is provided by cetylamine hydrofluoride, while for Optibond Solo, sodium hexafluorosilicate is its source. Both adhesives presented similar results, but higher than Syntac Sprint. Although fluoride presents a dynamic action mechanism on the progression/reduction of incipient caries lesions and a predictable adhesion to enamel has been achieved, the demineralization promoted by caries-like lesions adjacent to restorations bonded with fluoride-containing adhesives was not inhibited. Because of differences among the enamel microhardness around composite restorations and differences of microhardness along different distances from the cavity wall, both null hypotheses tested were rejected.

\section{CONCLUSIONS}

Enamel microhardness around composite restorations varied depending on the restorative technique. Fluoridecontaining adhesive systems were not necessarily associated with higher microhardness values. Close to the cavity wall (150 and $300 \mu \mathrm{m})$, the formation of demineralized areas was more evident.

\section{REFERENCES}

1- Burgess JO. Dental materials for the restoration of root surface caries. Am J Dent 1995;8(6):342-51.

2- Darvell BW. Materials science for dentistry. In: Resin restorative materials 6th ed. Hong Kong; 2000. p.111-39.

3- Dijkman GEHM, Arends J. Secondary caries in situ around fluoridereleasing light-curing composites: a quantitative model investigation on four materials with a fluoride content between 0 and 26 vol\%. Caries Res. 1992;26(5):351-7.

4- Ferracane JL, Mitchem JC, Adey JD. Fluoride penetration into the hybrid layer from a dentin adhesive. Am J Dent. 1998;11(1):23-8.

5- Ferrari M, Goracci G, Garcia-Godoy F. Bonding mechanism of three "one-bottle" systems to conditioned and unconditioned enamel and dentin. Am J Dent. 1997;10(5):224-30.

6- Francci C, Deaton TG, Arnold RR, Swift Jr EJ, Perdigão J, Bawden JW. Fluoride release from restorative materials and its effects on dentin demineralization. J Dent Res. 1999;78(10):1647-54.

7- Giannini M, Seixas CA, Reis AF, Pimenta LA. Six-month storagetime evaluation of one-bottle adhesive systems to dentin. J Esthet Restor Dent. 2003;15(1):43-8.

8- Hicks MJ, Flaitz CM, Silverstone LM. Secondary caries formation in vitro around glass ionomer restorations. Quintessence Int. 1986;17(9):527-32.

9- Kerber LJ, Donly KJ. Caries inhibition by fluoride-releasing primers. Am J Dent. 1993;6(5):216-8.

10- McLean JW, Wilson AD, Powis DR. The use of glass ionomer cements in bonding composite resins to dentine. Brit Dent J. 1985;158(8):410-4.

11- Montgomery DC. Design and analysis of experiments. $3^{\text {rd }}$ ed. New York: John Wiley \& Sons; 1991. p.134-5.

12- Papagiannoulis L, Kakaboura A, Eliades G. In vivo vs. in vitro anticariogenic behavior of glass-ionomer and resin composite restorative materials. Dent Mater. 2002;18(8):561-9.

13- Perdigão J, Ramos JC, Lambrechts P. In vitro interfacial relationship between human dentin and one-bottle dental adhesives. Dent Mater. 1997;13(4):218-27.

14- Pereira PNR, Inokoshi S, Tagami J. In vitro secondary caries inhibition around fluoride releasing materials. J Dent. 1998;26(56):505-10

15- Pimenta LAF, Giannini M, Marchi GM. Restauração com compósito em dentes posteriores submetidos à pulpotomia. Rev ABO Nac. 1999;7(2):90-4. 
16- Preston A J, Mair LH, Agalamany EA, Higham SM. Flouride release from aesthetic dental materials. J Oral Rehabil. 1999; 26(2):123-9.

17- Rebitski G, Donly KJ. Dentin pretreatment and caries inhibition by a fluoride-releasing resin. Am J Dent. 1993;6(4):204-6.

18- Segura A, Donly KJ, Quackenbush B. In vitro dentin demineralization inhibition effects of an experimental fluoridated HEMA and water wetting agent. J Oral Rehabil. 2000;27(6):532-7.

19- Serra MC, Cury JA. The in vitro effect of glass-ionomer cement restoration on enamel subjected to a demineralization and remineralization model. Quintessence Int. 1992;23(2):143-7.

20- Van Meerbeek B, Perdigão J, Lambrechts P, Vanherle G. The clinical performance of adhesives. J Dent. 1998;26(1):1-20.

21- Vargas MA, Cobb DS, Denehy GE. Interfacial micromorphology and shear bond strength of single-bottle primer/adhesives. Dent Mater. 1997;13(5):316-24 